\title{
Brood sex ratio in the Yellow-bellied Prinia (Prinia flaviventris)
}

\author{
Zhifeng Ding ${ }^{1 \dagger}$, Fang $\mathrm{Ji}^{1 \dagger}$, Qiuli Huang ${ }^{2}$, Longwu Wang ${ }^{3}$, Aiwu Jiang ${ }^{4}$, Chunlan Zhang ${ }^{1}$, Yongjun Feng ${ }^{1}$, \\ Yuan Tian', Huijian $\mathrm{Hu}^{1 *}$ and Wei Liang ${ }^{2^{*}}$ (1)
}

\begin{abstract}
Background: The adjustment of sex ratios in birds can occur at the egg and nestling stages. Previous studies showed that the sex ratio was affected by environmental factors and parental condition; it may result in seasonal and ecosystem differences.

Methods: In this study, the brood sex ratio of the Yellow-bellied Prinia (Prinia flaviventris) in the Nonggang area, Guangxi, southwestern China, was investigated during the breeding season from May to June in 2013 using PCR amplification from whole-genome DNA extracted from blood samples. A total of 31 nests of Yellow-bellied Prinia, including 132 brood fledglings and 31 pairs, were sampled.

Results: The results showed that the brood sex ratio of the Yellow-bellied Prinia was 1:1, and sex ratios of different nests were evenly distributed within the study area. No significant relationship was found between parental quality and nest characteristics with the brood sex ratio.

Conclusions: The present study indicated that no brood sex ratio bias in the Yellow-bellied Prinia highlighted the complexity of sex ratio adjustment in birds. In spite of our negative results, the lack of an association between brood sex ratio and parental quality and environmental factors in the Yellow-bellied Prinia provides valuable information on the adjustment of sex ratios in birds.
\end{abstract}

Keywords: Brood sex ratio, Parental quality, Yellow-bellied Prinia, Prinia flaviventris, Sex ratio adjustment

\section{Background}

Sex ratio is the ratio of the number of males to females in a population. According to the sex allocation theory, if no difference exists in the required reproductive investment and rewards for parental birds to produce either more male or more female offspring, the male-female ratio in their offspring should be 1:1 (Fisher 1930; Charnov 1982; Frank 1990). Variation in offspring sex ratio was a

\footnotetext{
*Correspondence: 13922339577@139.com;

liangwei@hainnu.edu.cn; liangw@hainan.net

${ }^{\dagger}$ Zhifeng Ding and Fang Ji contributed equally to this work

${ }^{1}$ Guangdong Key Laboratory of Animal Conservation and Resource

Utilization, Guangdong Public Laboratory of Wild Animal Conservation and Utilization, Guangdong Institute of Applied Biological Resources,

Guangzhou 510260, China

${ }^{2}$ Ministry of Education Key Laboratory for Tropical Plant and Animal

Ecology, College of Life Sciences, Hainan Normal University,

Haikou 571158, China

Full list of author information is available at the end of the article
}

key enigma in population biology, and was considered as major research subject in population ecology (Bouvier et al. 2016).

In theory, females (or parents) could manipulate sex ratio in several ways (Hasselquist and Kempenaers 2002), including manipulating the primary sex ratio (biasing the sex ratio of the ovulated eggs via a process taking place before or during ovulation, see details in Ewen et al. 2004), manipulating the order of laying (where early laid eggs are of one sex and later laid eggs are of the other sex, e.g. males come first, Ležalová et al. 2005), exerting sexdifferential investment in eggs (i.e. sex-differential distribution of maternal effects, e.g. large eggs should contain male embryos and small eggs contain female embryos, Mead et al. 1987; Cordero et al. 2000; Soma et al. 2007), using sex-differential parental investment rules when provisioning chicks (sex biased favoritism, Lessells 2002, e.g. mothers preferentially provisioned sons over 
daughters, whilst fathers showed no bias, Mainwaring et al. 2011). For primary sex ratio adjustment in birds, a combination of well-developed theoretical literature and rapid publication of empirical results has created controversial claims (reviewed in Ewen et al. 2004). For example, the Great Tit (Parus major) parents may tend to overproduce daughters as females are the dispersing sex in many passerine species (Gowaty 1993); however, using meta-analytical approach, Ewen et al. (2004) concluded that facultative control of offspring sex is not a characteristic biological phenomenon in breeding birds.

Also, adjustments to the sex ratio in avian species may occur at the egg and nestling stages, and adjustment in the brooding stage is called secondary sex ratio adjustment (Kilner 1998). Previous studies found that several factors contributed to affect parental care, then related to biases in avian brood sex ratios. These factors included the quality of the parents (parental condition, parental age and parental breeding experience), the quality of the external and social environment (such as habitat quality), and the number and asymmetry among the offspring (reviewed in Hasselquist and Kempenaers 2002). For example, Nager et al. (1999) found that the pre-fledging survival of male chicks was strongly reduced in all-male broods reared by parents in poor condition, but that of female chicks was affected neither by parental condition nor by brood sex composition. When parental age was taken into account, the proportion of males from older female Red-winged Blackbirds (Agelaius phoeniceus) was significantly greater than that of females, and the proportion of female offspring from young females was significantly higher than that of the male offspring (Blank and Nolan 1983). As for breeding experience, younger, less experienced pairs may tend to produce more sons than daughters when compared to older and more experienced pairs (Weimerskirch et al. 2000). Besides, sex allocation is sensitive to habitat quality, with high-quality territories producing broods biased towards sons and poor-quality territories producing broods biased towards daughters in passerine birds (Suorsa et al. 2003; Bell et al. 2014; Bouvier et al. 2016).

Specifically, bird body measurements such as body mass, tarsal length, etc. were commonly used and have been widely regarded as a good indicator of parental quality in previous studies (reviewed in Hasselquist and Kempenaers 2002). In Varied Tits (Parus varius), the number of male offspring in each nest was closely related to the tarsal length of male parental birds: larger males (such as those with a long tarsus) tend to have higher potential for acquiring resources, and their tarsal length is a heritable characteristic (Yamaguchi et al. 2004). Velando (2002) found that the proportion of sons in two-chick broods decreased with female mass and with female body condition at hatching.
Changes in sex ratios may affect the population structure, family composition, and mating relationships of animals, and may also affect their mating system, reproductive investment, and reproductive success (Grindstaff et al. 2001; Komdeur and Pen 2002; West and Sheldon 2002; Whittingham and Dunn 2005; Dietrich-Bischoff et al. 2006; Korsten et al. 2006). Sex allocation theory is well defined (Fisher 1930; Frank 1990) but its empirical support in vertebrates is still ambiguous.

The Yellow-bellied Prinia belongs to the order Passeriformes and was widely distributed in southern China (Zheng 2011). These birds have relatively small bodies and show subtle sexual dimorphism in their upper back color (Yang et al. 2013). Contrary to most of birds, these birds were characterized by inverse-changed tails (a shorter tail in the breeding season than in the nonbreeding season, Zhao 2001), high parental investment in the breeding season (i.e. time overlap between spring moulting and breed activities, high feeding frequencies than that of similar body size of the same family, two breeding attempts in the breeding season, and relatively higher annual productivity compared with nine passerine birds of similar body mass, Ding et al. 2007, 2016, 2017). In this scenario, these life-history traits of the Yellow-bellied Prinia might determine its brood sex ratios to some extent. The aim of this study is to investigate sex-ratio in Yellow-bellied Prinia using molecular sexing techniques and answer the following questions: (1) Does the Yellowbellied Prinia have deviant brood sex ratios? (2) If their brood sex ratio is deviant, are there correlations between the brood sex ratio and physical characteristics of the parent or with the status of local natural resources? (3) Is there any correlation between the physical characteristics of the parents and brood?

\section{Methods}

\section{Study area}

The study was carried out in the Nonggang National Nature Reserve, Guangxi, southwestern China $\left(23^{\circ} 39^{\prime} \mathrm{N}\right.$, $107^{\circ} 04^{\prime} \mathrm{E}$ ), during the breeding season from May to June in 2013. This area was the transition of tropical zone and subtropical zone with subtropical monsoonal climate, characterized by warm temperatures and abundant rainfall. The mean annual temperature is $22{ }^{\circ} \mathrm{C}$, and annual precipitation is $1150-1550 \mathrm{~mm}$, with the majority of rainfall occurring in May to September (Liang et al. 1985). Our study site is located at open artificial sugarcane fields, and Saccharum sinense is the main crop there. $S$. sinense is also an important plant used for nesting by most local birds (for more details, see Yang et al. 2014). Among them, Yellow-bellied Prinias mainly compete with two bird species for nesting sites in the sugarcane plants, namely the Plain Prinia (Prinia inornata) and the 
Common Tailorbird (Orthotomus sutorius) (Huang et al. 2015).

\section{Study species}

The Yellow-bellied Prinia (hereafter prinia) is widely distributed in southern China, including Taiwan and Hainan islands; both males and females have a shorter tail in the breeding season than in the non-breeding season (Zhao 2001). Their courtship begins in early March, and their nesting and egg-laying season lasts from early April to late June. Both male and female birds participate in nesting in low bushes or small shrubs. Nests have an irregular spherical shape, sitting approximately $1 \mathrm{~m}$ above the ground, with a side-opening hole in the upper part of the nest. Their eggs are mostly red (many different shades of red in different individuals or nests), usually oval. Nest construction by both parents lasts for 5-7 days, and egg laying occurs at the next day of finishing the nest-building or at intervals. Once egg laying starts, the Yellowbellied Prinia lays eggs at 6:00-8:00 a.m. every day until finished. Clutch size of the Yellow-bellied Prinia is usually five, incubation period lasts for 11-14 days, and their brood period lasts for 11-12 days. The chickens of the Yellow-bellied Prinia are altricial (Ding et al. 2007, 2016, 2017; Yang et al. 2013, 2014; Wang et al. 2016).

\section{Field data collection}

Once an egg was found in a nest, the nest was observed every other day to monitor it for hatching. The location and elevation of each nest were recorded using a GPS. We sampled nestlings from nests when they were 9 days old and used mist nets to capture parental birds at the same time. Immediately after capture in the mist net the adult birds were quickly removed to avoid injuring them. We used disposable lancets to collect samples from brachial veins on the underside of the birds' wings. Blood was collected using medical cotton swabs, placed in freezing vials with $96 \%$ analytical ethanol, and stored frozen in preparation for DNA extraction in the lab. A total of 31 families involving 62 adults and 132 offspring were used for the sex ratio analysis. Further, physical characteristics of indicators in 17 nests (32 adults belonging to 16 nests and 72 offspring belonging to 17 nests) were collected. Specifically, we collected data on body weight (g), tarsal length $(\mathrm{mm})$, wing length $(\mathrm{mm})$, tail length $(\mathrm{mm})$, and gape $(\mathrm{mm})$ and body length $(\mathrm{mm})$ of parental birds, and also collected data on body weight $(\mathrm{g})$ and tarsal length $(\mathrm{mm})$ of the nestlings.

\section{Sex determination}

We confirmed the sex of parents and nestlings using established PCR testing methods. Sex was determined using PCR amplification from the whole-genome
DNA extracted from blood. Whole-genome DNA was extracted using a reagent kit (E.Z.N.A. ${ }^{\mathrm{TM}}$ Micro Elute Genomic DNA Kit, OMEGA, USA). We then amplified a linked gene, CHD-W, in the W chromosome and linked gene, $\mathrm{CHD}-\mathrm{Z}$, in the $\mathrm{Z}$ chromosome using a universal primer pair for non-ratite birds P2 (5'-TCTG CATCGCTAAATCCTTT- $3^{\prime}$ ) and P8 (5'-CTCCCAAG GATGAGRAAYTG-3'; Griffiths et al. 1998). Amplification conditions were as follows: denaturation at $94{ }^{\circ} \mathrm{C}$ for $2 \mathrm{~min} ; 30$ cycles of denaturation at $94{ }^{\circ} \mathrm{C}$ for $1 \mathrm{~min}$; replication at $50{ }^{\circ} \mathrm{C}$ for $30 \mathrm{~s}$; extension at $72{ }^{\circ} \mathrm{C}$ for $1 \mathrm{~min}$; final extension at $72{ }^{\circ} \mathrm{C}$ for $10 \mathrm{~min}$. Each $25 \mu \mathrm{L}$ PCR aliquot contained $12.5 \mu \mathrm{L}$ of PCRMix (GoTaq Green Master Mix, Promega, USA), $0.5 \mu \mathrm{L}$ of each primer, $5 \mu \mathrm{L}$ of DNA template, and $6.5 \mu \mathrm{L}$ of $\mathrm{ddH}_{2} \mathrm{O}$. Amplification products were electrophoresed on $2 \%$ agarose gel for $1 \mathrm{~h}$. To determine the gender of nestlings, the appearance of two bands indicated the bird was a female and one band indicated a male.

\section{Data analysis}

At the population level, sex ratio is expressed as the number of male nestlings versus the number of female nestlings. That is, sex ratio $(\mathrm{SR})=$ male/female ( $\delta^{*}:$ ) ). We used Chi-squared $\left(x^{2}\right)$ test to determine the difference between measured sex ratios and the theoretical value of 1:1. At the nest level, the sex ratio is the proportion of male fledglings in broods. And the difference from the theoretical value (0.5) was also analyzed with Chi-squared $\left(\chi^{2}\right)$ test. When determining the brood sex ratio at the nest level, the proportion of male fledglings in each nest was considered a dependent variable, and each nest was treated individually. A generalized linear model with binomial error structure and a general linear mixed model (when the response has a normal distribution) were used to analyze the effects of different factors (body weight, tarsal length, wing length, tail length, gape and body length of parental birds) on the secondary sex ratio, brood body weight and tarsus length. A $t$ test was used to analyze the difference of sex ratios of fledglings born in May and in June (the relationship between the nest-level hatching time and the proportion of males). In this analysis, the time period was divided into May and June. All parameters are presented as the mean \pm standard deviation (SD). GLM analysis was carried out using the stats package in R 3.0.1 (R Development Core Team 2011), and other analyses by SPSS 19.0.

\section{Results}

\section{Population-level brood sex ratio}

Based on the 132 fledglings sampled, the population sex ratio was 1:1 ( $0^{*}:$ ?), and the ratio was 1.39:1 in May and 0.79:1 in June. These sex ratio did not significantly deviate 
from a 1:1 ratio $\left(\chi^{2}=1.157, p=0.282\right.$ in May; $\chi^{2}=0.76$, $p=0.383$ in June). From the collected samples, 72 individual fledglings from 17 nests were further used in the analysis of sex ratio and parental index. The sex ratio for these 17 nests was 1.12:1, and this ratio did not significantly deviate from a 1:1 ratio $\left(x^{2}=0.163, p=0.686\right)$. There was no significant difference in female and male body weight ratio $\left(1: 1.02, \chi^{2}=0.023, p=0.879\right)$, and tarsal length ratio $\left(1: 1.1, \chi^{2}=0.032, p=0.858\right)$ of fledglings in these 17 nests.

\section{Nest-level brood sex ratio}

At the nest level, the brood sex ratio is represented by the proportion of males in each nest; the sex ratio was $0.509 \pm 0.263$, and this secondary sex ratio did not significantly deviate from $0.5\left(x^{2}=0.003, p=0.96\right)$. The sex ratio of fledglings born in May was $0.578 \pm 0.281$, and in June was $0.459 \pm 0.244$. These ratios did not significantly deviate from $0.5\left(x^{2}=0.015, p=0.903\right.$; $X^{2}=0.011, p=0.916$, respectively), and the difference sex ratios of fledglings born in May and in June was not significant $(t=1.244, \mathrm{df}=28, p=0.224)$. Nests with different nest sex ratios were evenly distributed spatially (Fig. 1).

\section{Correlation between parental body conditions}

Pearson correlation analysis showed that wing, body, and tail lengths of parent Yellow-bellied Prinia were positively correlated to each other while other characteristics were not correlated (Table 1). The relationship between parental quality and brood sex ratio was not correlated (Table 2). Only negative correlations existed between female tarsal length and nestlings weight $(p=0.0268$; Table 3), and other factors such as body weight, wing length $(\mathrm{mm})$, etc. of parental birds did not affect nestling weight. Also, negative correlations existed between tarsal length of females and tarsus length of nestlings $(p=0.0228$; Table 4$)$, and other factors such as body weight, wing length $(\mathrm{mm})$, etc. of parental birds did not affect nestling tarsus length.

\section{Discussion}

The present study showed that the brood sex ratio of the Yellow-bellied Prinia is 1:1, the parental body condition were not correlated with the brood sex ratio. Sex ratios of different nests were diffusely distributed within the study area, but the brood sex ratio was coincident with the sex allocation theory. Our results suggest that the relationship among brood sex ratio, parental quality and

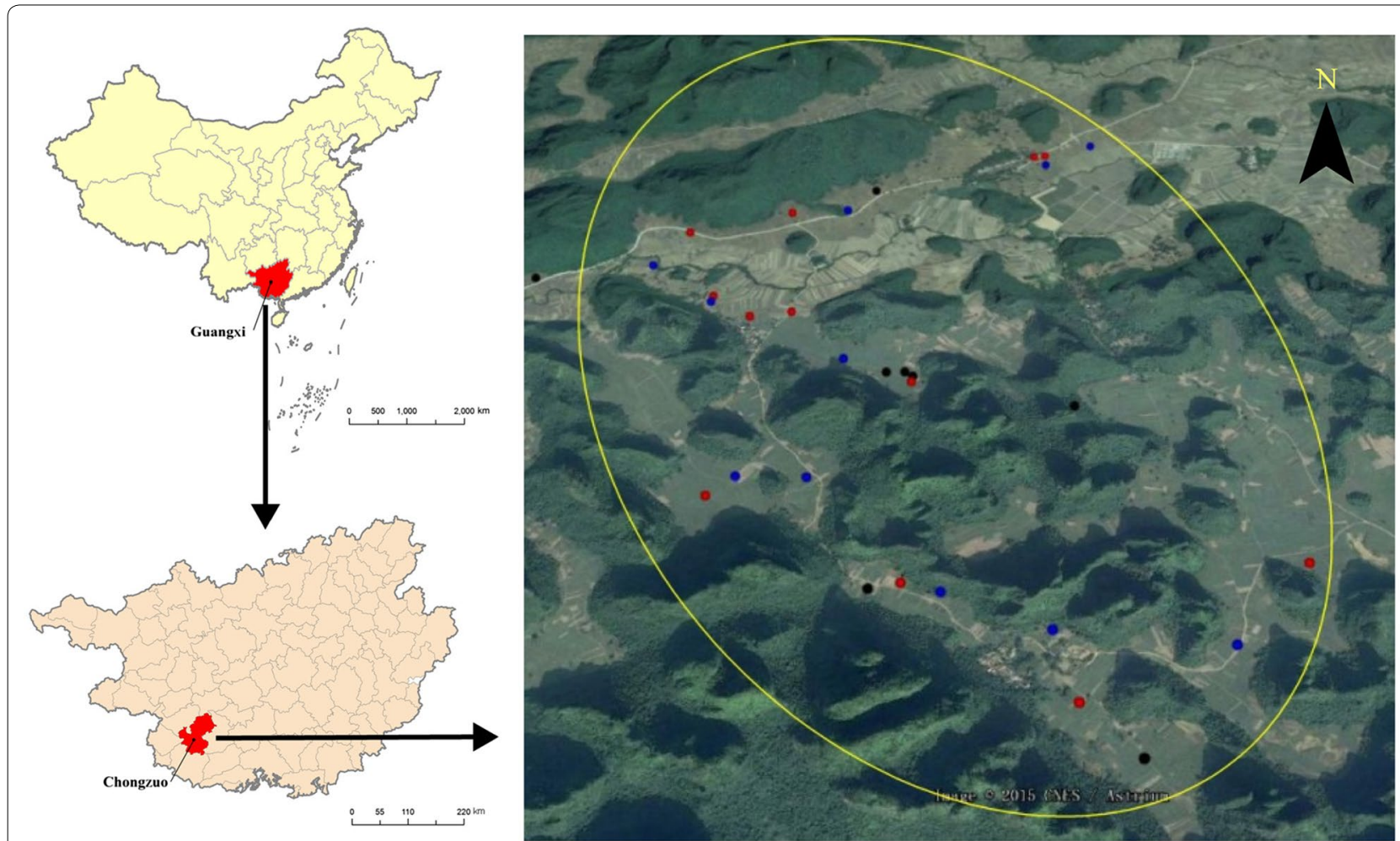

Fig. 1 Nest distribution of the Yellow-bellied Prinia (Prinia flaviventris). Blue, black, and red dots denote nest sex ratios of $<0.5,=0.5$, and $>0.5$, respectively 
Table 1 Relationship between parental bird body indicators ( $n=32$ nests)

\begin{tabular}{|c|c|c|c|c|c|c|}
\hline & Weight (g) & Tarsus length (mm) & Wing length $(\mathrm{mm})$ & Tail length (mm) & Gape (mm) & Body length $(\mathrm{mm})$ \\
\hline Body weight (g) & 1 & 0.119 & 0.141 & 0.142 & 0.141 & 0.164 \\
\hline Tarsus (mm) & & 1 & 0.257 & 0.297 & 0.109 & 0.349 \\
\hline Wing length (mm) & & & 1 & $0.481^{*}$ & -0.149 & 0.225 \\
\hline Tail length (mm) & & & & 1 & 0.220 & $0.691^{*}$ \\
\hline Gape (mm) & & & & & 1 & 0.349 \\
\hline Body length (mm) & & & & & & 1 \\
\hline
\end{tabular}

* Pearson correlation is significant at the 0.01 level (two-tailed)

Table 2 Brood sex of the Yellow-bellied Prinia (Prinia flaviventris) in relation to parental quality ( $n=72$ fledglings from 16 nests)

\begin{tabular}{lrllrl}
\hline Factors & Estimate & Error & df & \multicolumn{1}{l}{$\boldsymbol{F}$} & $\boldsymbol{p}$ \\
\hline Weight & -0.900723 & 1.674572 & 31 & -0.538 & 0.591 \\
Body length & 0.014415 & 0.064103 & 31 & 0.225 & 0.822 \\
Tail length & -0.000361 & 0.115028 & 31 & -0.003 & 0.997 \\
Wing length & 0.017930 & 0.350397 & 31 & 0.051 & 0.959 \\
Tarsus & -0.020326 & 0.515573 & 31 & -0.039 & 0.969 \\
Gape & 0.027883 & 0.788965 & 31 & 0.035 & 0.972 \\
\hline
\end{tabular}

The best fitting model was shown above. The weight, tarsal length, wing length, tail length, gape and body length of parental birds were included in the model as random factors, sex ratio as independent variable

Table 3 Mean body weight of fledglings of the Yellow-bellied Prinia (Prinia flaviventris) in relation to parental quality

\begin{tabular}{|c|c|c|c|c|c|}
\hline Predictor & Estimate & SE & df & $F$ & $p$ \\
\hline Weight ( $₫$ ) & 1.41813 & 2.08176 & 15 & 0.681 & 0.513 \\
\hline Wing length ( $₫$ ) & 0.10042 & 0.37692 & 15 & 0.266 & 0.796 \\
\hline Tail length (đ̋) & 0.10144 & 0.13138 & 15 & 0.772 & 0.460 \\
\hline Tarsus (ô) & -0.12486 & 0.57575 & 15 & -0.217 & 0.833 \\
\hline Gape (ð) & -1.22274 & 0.89775 & 15 & -1.362 & 0.206 \\
\hline Body length ( $\left.{ }^{*}\right)$ & 0.02410 & 0.09502 & 15 & 0.254 & 0.805 \\
\hline Weight (o) & 2.81313 & 1.28387 & 15 & 2.191 & 0.0561 \\
\hline Wing length (\%) & 0.74688 & 0.42973 & 15 & 1.738 & 0.1162 \\
\hline Tail length (o) & -0.04932 & 0.10551 & 15 & -0.467 & 0.6513 \\
\hline Tarsus (o) & -1.67433 & 0.63368 & 15 & -2.642 & $0.0268^{*}$ \\
\hline Gape () & 1.43417 & 0.77106 & 15 & 1.860 & 0.0958 \\
\hline Body length (\$) & -0.15664 & 0.11699 & 15 & -1.339 & 0.2134 \\
\hline
\end{tabular}

The best fitting model was shown above. The weight, tarsal length, wing length, tail length, gape and body length of parental birds were included in the model as random factors, body weight of fledglings as independent variable

* Positive and negative effective factors represent heavier or lighter mean nest weight at $p<0.05$, respectively

nest distribution in the prinia may be context-dependent, highlighting the complexity of sex ratio adjustment in birds.
Table 4 Mean tarsus of fledglings of the Yellow-bellied Prinia (Prinia flaviventris) in relation to parental quality

\begin{tabular}{|c|c|c|c|c|c|}
\hline Factor & Estimate & SE & df & $F$ & $p$ \\
\hline Weight (ổ) & 2.32292 & 5.69813 & 15 & 0.408 & 0.693 \\
\hline Wing length (ס̋) & 0.35965 & 1.03168 & 15 & 0.349 & 0.735 \\
\hline Tail length (ð̋) & 0.29032 & 0.35960 & 15 & 0.807 & 0.440 \\
\hline Tarsus (ํ) & -0.12749 & 1.57592 & 15 & -0.081 & 0.937 \\
\hline Gape (ð̋) & -3.10323 & 2.45729 & 15 & -1.263 & 0.238 \\
\hline Body length (ð) & 0.04211 & 0.26009 & 15 & 0.162 & 0.875 \\
\hline Weight (ㅇ) & 7.75522 & 3.46074 & 15 & 2.241 & 0.0518 \\
\hline Wing length (ㅇ) & 1.99550 & 1.15836 & 15 & 1.723 & 0.1190 \\
\hline Tail length (o) & -0.09771 & 0.28442 & 15 & -0.344 & 0.7391 \\
\hline Tarsus (ㅇ) & -4.68197 & 1.70813 & 15 & -2.741 & $0.0228^{*}$ \\
\hline Gape (ㅇ) & 3.93638 & 2.07844 & 15 & 1.894 & 0.0908 \\
\hline Body length (o) & -0.44973 & 0.31534 & 15 & -1.426 & 0.1876 \\
\hline
\end{tabular}

The best fitting model was shown above. The weight, tarsal length, wing length tail length, gape and body length of parental birds were included in the model as random factors, tarsal length of fledglings as independent variable

* Positive and negative effective factors represent longer or shorter mean tarsus length at $p<0.05$, respectively

Previous work with other species revealed that the brood sex ratio is expected to increase inclusive fitness of birds in varying conditions (Howe 1977; Dijkstra et al. 1990; Smallwood and Smallwood 1998; Korpimaki et al. 2000; Szekely et al. 2004). For example, investigations of Quiscalus quiscula (Howe 1977), Charadrius alexandrinus (Szekely et al. 2004), and small falcons (Dijkstra et al. 1990; Smallwood and Smallwood 1998; Korpimaki et al. 2000) have shown that the proportion of male offspring decreases later in the period of reproduction, while in large falcons, the proportion of male offspring gradually increases later in the period of reproduction (Daan et al. 1996; Olsent and Cockburn 2004). This type of seasonal change is correlated with the environment and the abundance of food. In size-dimorphic species, environmental sensitivity can indeed be sex-dependent (Jones et al. 2009), with evidence of direct male-specific toxic effects of diverse pollutants in a number of bird species (Cichon et al. 2005; Svenson et al. 2007). It is generally believed that the gender with relatively a larger body is more sensitive to 
poor environmental conditions because they require more energy during growth (Pérez et al. 2006; Barros et al. 2013), and the gender with a relatively larger body has a competitive advantage within the nest, and thus can survive in adverse conditions (Oddie 2000). The Yellow-bellied Prinia has no obvious sexual dimorphism, and differences between female and male fledglings are not significant. In our results, the ratio of male fledglings also decreased slightly later in the reproductive period (the population sex ratio in May was 1.39:1, and in June was 0.79:1), possibly caused by the following factors: (1) difference of parental condition between May and June, and (2) changes in habitat quality between May and June. Possibly, there exist differences in habitat quality between May and June; besides, the Yellow-bellied Prinia finishes spring moulting in the end of May (Ding et al. 2015), and time overlaps between spring moulting and breeding activities that occur in May, so parental condition of the Yellow-bellied Prinia might have difference between May and June.

This can also explain why the number of females increases slightly later in the period of reproduction. Since resource abundance is not in the scope of this study and we still lack direct evidence to favor one or more of the processes discussed above, we do not exclude that these explanations are not exclusive and the observed bias in sex-ratio may also accumulate from fertilization to fledging. The attractiveness and quality of partners have been acknowledged as key factors of sex ratio variation during pre- or post-parturition offspring development (Becker et al. 2008; Taff et al. 2011; Pryke and Rollins 2012). Our results may not concur with such expectations as our estimates of partners' body condition (weight, tarsal length, wing length, tail length, gape and body length) were not significant predictors of brood sex ratio. Our results showed that the quality of the male Yellow-bellied Prinia was not correlated with the sex ratio or quality of the offspring. We also found that the maternal tarsal length was negatively correlated with body weight and tarsal length of fledglings. Thus, in the Yellow-bellied Prinia, tarsal length is a heritable feature, which is only correlated with the female of the species but is unrelated to the sex ratio of fledglings. Perhaps, our sample size for adult body condition was low, and we need more data to test the relationships.

\section{Conclusions}

In conclusion, our results showed that the brood sex ratio of the Yellow-bellied Prinia was 1:1, and the parental quality was not correlated with the sex ratio of the offspring. Our results indicated no brood sex ratio bias in this bird species, highlighting the complexity of sex ratio adjustment in birds. In spite of our negative results, the lack of an association between brood sex ratio and parental quality and environmental factors in the Yellowbellied Prinia may provide valuable information on the adjustment of sex ratios in birds.

\section{Authors' contributions}

$\mathrm{HH}$ and WL conceived and designed the study. QH, LW and AJ sampled and collected data in the field. ZD, FJ, YF and YT performed molecular work in the lab. ZD, CZ and FJ analyzed the data. ZD, FJ, HH and WL wrote the manuscript. All authors read and approved the final manuscript.

\section{Author details}

${ }^{1}$ Guangdong Key Laboratory of Animal Conservation and Resource Utilization, Guangdong Public Laboratory of Wild Animal Conservation and Utilization, Guangdong Institute of Applied Biological Resources, Guangzhou 510260, China. ${ }^{2}$ Ministry of Education Key Laboratory for Tropical Plant and Animal Ecology, College of Life Sciences, Hainan Normal University, Haikou 571158, China. ${ }^{3}$ School of Life Sciences, Guizhou Normal University, Guiyang 550001 China. ${ }^{4}$ College of Forestry, Guangxi University, Nanning 530004, China.

\section{Acknowledgements}

We would like to thank lan Will from University of California, Berkeley, USA, Demeng Jiang and Yungao Hu for their assistance with fieldwork, and Zhixin Zhou and Daoying Lan for their comments on an earlier version of the manuscript. This work was supported by the National Natural Science Foundation of China (Nos. 31472013 to WL, 31660617 to LW, 31460567 to AJ, and 31572257 to $\mathrm{HH}$ ), Key Scientific and Technological Project of Science and Information Technology of Haizhu district, Guangzhou City (2013-cg-03 to ZD, 2014-cg-17 to $\mathrm{HH}$ ), and GDAS Special Project of Science and Technology Development (2017GDASCX-0107).

\section{Competing interests}

The authors declare that they have no competing interests.

\section{Ethical statements}

The experiments in this study comply with the current laws of China, where they were performed. Fieldwork including capturing and sampling birds was carried out under the permission from the Nonggang National Nature Reserve, Guangxi, China. Experimental procedures were in agreement with the Animal Research Ethics Committee of Hainan Provincial Education Centre for Ecology and Environment, Hainan Normal University (Permit No. HNECEE-2012-002).

Received: 31 January 2017 Accepted: 22 June 2017

Published online: 30 June 2017

\section{References}

Barros Á, Álvarez D, Velando A. Climate influences fledgling sex ratio and sexspecific dispersal in a seabird. PLoS ONE. 2013;8:e71358.

Becker PH, Ezard THG, Ludwigs JD, Sauer-Gürth H, Wink M. Population sex ratio shift from fledging to recruitment: consequences for demography in a philopatric seabird. Oikos. 2008;117:60-8.

Bell SC, Owens IP, Lord AM. Quality of breeding territory mediates the influence of paternal quality on sex ratio bias in a free-living bird population. Behav Ecol. 2014;25:352-8.

Blank JL, Nolan V. Offspring sex ratio in red-winged blackbirds is dependent on maternal age. Proc Natl Acad Sci USA. 1983;80:6141-5.

Bouvier JC, Boivinb T, Charmantierc A, Lambrechtsc M, Lavigne C. More daughters in a less favourable world: breeding in intensively-managed orchards affects tertiary sex-ratio in the great tit. Basic Appl Ecol. 2016;17:638-47.

Charnov EL. The theory of sex allocation. Princeton: Princeton University Press; 1982.

Cichoń M, Sendecka J, Gustafsson L. Male-biased sex ratio among unhatched eggs in great tit Parus major, blue tit P. caeruleus and collared flycatcher Ficedula albicollis. J Avian Biol. 2005;36:386-90.

Cordero PJ, Griffith SC, Aparicio JM, Parkin DT. Sexual dimorphism in house sparrow eggs. Behav Ecol Sociobiol. 2000;48:353-7. 
Daan S, Dijkstra C, Weissing FJ. An evolutionary explanation for seasonal trends in avian sex ratios. Behav Ecol. 1996;7:426-30.

Ding Z, Tang S, Zhang J, Chen Y, Hu H. Autumn moulting of the adults of Yellow-bellied Prinia, Prinia flaviventris. Chin J Zool. 2007;42:28-33 (in Chinese)

Ding Z, Li K, Tang S, Hu H. Spring moulting and tail changes of two wren warbler species. Chin J Zool. 2015;50:493-8 (in Chinese)

Ding Z, Liang J, Pan X, Hu H. Feeding behavior and nestling growth of Yellow-bellied Prinia (Prinia flaviventris). Chin J Zool. 2016;51:969-76 (in Chinese)

Ding Z, Liang J, Zhou Z, Feng Y, Hu H. Comparisons of breeding parameters of two Prinia species. Chin J Zool. 2017;52:417-22 (in Chinese).

Dietrich-Bischoff V, Schmoll T, Winkel W, Krackow S, Lubjuhn T. Extra-pair paternity, offspring mortality and offspring sex ratio in the socially monogamous coal tit (Parus ater). Behav Ecol Sociobiol. 2006;60:563-71.

Dijkstra C, Daan S, Buker JB. Adaptive seasonal variation in the sex ratio of kestrel broods. Funct Ecol. 1990;4:143-7.

Ewen JG, Cassey P, Moller AP. Facultative primary sex ratio variation: a lack of evidence in birds? Proc R Soc B. 2004;271:1277-82.

Fisher R. The genetical theory of natural selection. London: Oxford University Press; 1930.

Frank SA. Sex allocation theory for birds and mammals. Ann Rev Ecol Syst. 1990;21:13-55.

Griffiths R, Double MC, Orr K, Dawson RJ. A DNA test to sex most birds. Mol Ecol. 1998;7:1071-5.

Grindstaff JL, Buerkle AC, Casto JM, Nolan V, Ketterson ED. Offspring sex ratio is unrelated to male attractiveness in dark-eyed juncos (Junco hyemalis). Behav Ecol Sociobiol. 2001;50:312-6.

Gowaty PA. Differential dispersal, local resource competition, and sex ratio variation in birds. Am Nat. 1993;141:263-80.

Hasselquist D, Kempenaers B. Parental care and adaptive brood sex ratio manipulation in birds. Philos Trans R Soc B. 2002;357:363-72.

Howe HF. Sex-ratio adjustment in the common grackle. Science. 1977;198:744-6.

Huang Q, Wang L, Yang C, Liang W. Comparison of nest site selection of Orthotomus sutorius and O. cucullatus. China. J Ecol. 2015;34:2861-5 (in Chinese).

Jones KS, Nakagawa S, Sheldon BC. Environmental sensitivity in relation to size and sex in birds: meta-regression analysis. Am Nat. 2009;174:122-33.

Kilner R. Primary and secondary sex ratio manipulation by zebra finches. Anim Behav. 1998;56:155-64.

Komdeur J, Pen I. Adaptive sex allocation in birds: the complexities of linking theory and practice. Philos Trans R Soc Lond B. 2002;357:373-80.

Korpimaki E, May CA, Parkin DT, Wetton JH, Wiehn J. Environmental- and parental condition-related variation in sex ratio of kestrel broods. J Avian Biol. 2000;31:128-34.

Korsten P, Lessells CKM, Mateman AC, van der Velde M, Komdeur J. Primary sex ratio adjustment to experimentally reduced male UV attractiveness in blue tits. Behav Ecol. 2006;17:539-46.

Lessells CM. Parentally biased favouritism: why should parents specialize in caring for different offspring? Philos Trans R Soc B. 2002;357:381-403.

Ležalová R, Tkadlec E, Oborník M, Šimek J, Honza M. Should males come first? The relationship between offspring hatching order and sex in the blackheaded gull Larus ridibundus. J Avian Biol. 2005;36:478-83.

Liang CF, Liang JY, Liu LF, Mo XL. A report on the exploration of the flora of Longgang. Guihaia. 1985;5:191-209.

Mainwaring MC, Lucy D, Hartley IR. Parentally biased favouritism in relation to offspring sex in zebra finches. Behav Ecol Sociobiol. 2011;65:2261-8.

Mead PS, Morton ML, Fish BE. Sexual dimorphism in egg size and implications regarding facultative manipulation of sex in mountain white-crowned sparrows. Condor. 1987;89:798-803.

Nager RG, Monaghan P, Griffiths R, Houston DC, Dawson R. Experimental demonstration that offspring sex ratio varies with maternal condition. Proc Natl Acad Sci USA. 1999;96:570-3.

Oddie KR. Size matters: competition between male and female great tit offspring. J Anim Ecol. 2000;69:903-12.

Olsent PD, Cockburn A. Female-biased sex allocation in peregrine falcons and other raptors. Behav Ecol Sociobiol. 2004;28:417-23.

Pérez C, Velando A, Domínguez J. Parental food conditions affect sex-specific embryo mortality in the yellow-legged gull (Larus michahellis). J Ornithol. 2006;147:513-9.
Pryke SR, Rollins LA. Mothers adjust offspring sex to match the quality of the rearing environment. Proc R Soc B. 2012;279:4051-7.

R Development Core Team. R: A language and environment for statistical computing. R Foundation for Statistical Computing, Vienna. 2011. http:// www.R-project.org/.

Smallwood PD, Smallwood J. Seasonal shifts in sex ratios of fledgling American kestrels (Falco parverius paulus): the early bird hypothesis. Evol Ecol. 1998;12:839-53.

Soma M, Saito DS, Hasegawa T, Okanoya K. Sex-specific maternal effect on egg mass, laying order, and sibling competition in the Bengalese finch (Lonchura striata var. domestica). Behav Ecol Sociobiol. 2007;61:1695-705.

Szekely T, Cuthill IC, Yezerinac S, Griffiths R, Kis J. Brood sex ratio in the Kentish plover. Behav Ecol. 2004;15:58-62.

Svenson M, Rintamäki PT, Birkhead TR, Griffith SC, Lundberg A. Impaired hatching success and male-biased embryo mortality in Tree Sparrows. J Ornithol. 2007;148:117-22.

Suorsa P, Helle H, Huhta E, Jäntti A, Nikula A, Hakkarainen H. Forest fragmentation is associated with primary brood sex ratio in the treecreeper (Certhia familiaris). Proc R Soc B. 2003;270:2215-22.

Taff CC, Freeman-Gallant CR, Dunn PO, Whittingham LA. Relationship between brood sex ratio and male ornaments depends on male age in a warbler. Anim Behav. 2011;81:619-25.

Velando A. Experimental manipulation of maternal effort produces differential effects in sons and daughters: implications for adaptive sex ratios in the blue-footed booby. Behav Ecol. 2002;13:443-9.

Wang L, Liang W, Yang C, Cheng S, Hsu Y, Lu X. Egg rejection and clutch phenotype variation in the plain prinia Prinia inornata. J Avian Biol. 2016;47:788-94.

West SA, Sheldon BC. Constraints in the evolution of sex ratio adjustment. Science. 2002;295:1685-8.

Weimerskirch H, Barbraud C, Lys P. Sex differences in parental investment and chick growth in wandering albatrosses: fitness consequences. Ecology. 2000;81:309-18.

Whittingham LA, Dunn PO. Effects of extra-pair and within-pair reproductive success on the opportunity for selection in birds. Behav Ecol. 2005;16:138-44.

Yamaguchi N, Kawano KK, Eguchi K, Yahara T. Facultative sex ratio adjustment in response to male tarsus length in the Varied Tit Parus varius. Ibis. 2004;146:108-13.

Yang C, Wang L, Hsu YC, Antonov A, Moksnes A, Røskaft E, Liang W, Stokke $B G$. UV reflectance as a cue in egg discrimination in two prinia species exploited differently by brood parasites in Taiwan. Ibis. 2013;155:571-5.

Yang C, Wang L, Cheng SJ, Hsu YC, Liang W, Møller AP. Nest defenses and egg recognition of Yellow-bellied Prinia against cuckoo parasitism. Naturwissenschaften. 2014;101:727-34.

Zhao Z. A handbook of the birds of China: Passerines. Changchu: Jilin Science and Technology Press; 2001 (in Chinese).

Zheng G. A checklist on the classification and distribution of the birds of China. Beijing: Science Press; 2011 (in Chinese).

\section{Submit your next manuscript to BioMed Central and we will help you at every step:}

- We accept pre-submission inquiries

- Our selector tool helps you to find the most relevant journal

- We provide round the clock customer support

- Convenient online submission

- Thorough peer review

- Inclusion in PubMed and all major indexing services

- Maximum visibility for your research

Submit your manuscript at www.biomedcentral.com/submit
() Biomed Central 